\title{
Meta-Analysis of Endovascular Treatment for Acute M2 Occlusion
}

\author{
Chul Ho Kim, M.D., Sung-Eun Kim, M.D., ${ }^{2}$ Jin Pyeong Jeon, M.D. ${ }^{3-5}$ \\ Department of Neurology, Hallym University College of Medicine, Chuncheon, Korea \\ Department of Emergency Medicine, 2 Seoul Emergency Operations Center, Seoul, Korea \\ Institute of New Frontier Stroke Research, ${ }^{3}$ Hallym University College of Medicine, Chuncheon, Korea \\ Genetic and Research Incorporation, ${ }^{4}$ Chuncheon, Korea \\ Department of Neurosurgery, ${ }^{5}$ Hallym University College of Medicine, Chuncheon, Korea
}

Objective : Endovascular treatment (EVT) outcomes for acute M2 segment of middle cerebral artery occlusion remains unclear because most results are obtained from patients with large artery occlusion in the anterior circulation. The objective of this study was to assess procedural outcomes for acute M2 occlusion and compare outcomes according to thrombus location (M1 vs. M2).

Methods : A systematic review was performed for online literature published from January 2004 to December 2016. Primary outcome was successful recanalization rate and symptomatic intracranial hemorrhage $(\mathrm{S}-\mathrm{ICH})$ after the procedure. A fixed effect model was used if heterogeneity was less than $50 \%$.

Results : Eight articles were included. EVT showed successful recanalization rate of $69.1 \%$ (95\% confidence interval [Cl], 54.9$80.4 \%)$ and $\mathrm{S}-\mathrm{ICH}$ rate of $6.1 \%(95 \% \mathrm{Cl}, 4.5-8.3 \%)$. The rates of good clinical outcome at 3 months and mortality were $59.4 \%(95 \%$ $\mathrm{Cl}, 49.9-68.2 \%)$ and $14.9 \%(95 \% \mathrm{Cl}, 11.4-19.3 \%)$, respectively. According to thrombus location (M1 vs. $\mathrm{M2}$ ), successful recanalization (odds ratio [OR], 1.539; 95\% Cl, 0.293-8.092; $p=0.610)$ and S-ICH (OR, 1.313; $95 \% \mathrm{Cl}, 0.603-2.861 ; p=0.493)$ did not differ significantly. Good clinical outcome was more evident in M2 occlusion after EVT than that in M1 occlusion (OR, 1.639; 95\% Cl, 1.135-2.368; $p=0.008)$. However, mortality did not differ significantly according to thrombus location ( $\mathrm{OR}, 0.788 ; 95 \% \mathrm{Cl}, 0.486-1.276 ; p=0.332)$.

Conclusion : EVT seems to be technically feasible for acute M2 occlusion. Direct comparative studies between EVT and medical treatment are needed further to find specific beneficiary group after EVT in patient with M2 occlusion.

Key Words : Infarction · Middle cerebral artery · Stroke · Thrombectomy.

\section{INTRODUCTION}

Endovascular treatment (EVT) has been widely performed for acute ischemic stroke with better outcome than medical treatment ${ }^{9)}$. According to patient data from five randomized trials (MR CLEAN, ESCAPE, REVASCAT, SWIFT PRIME, and EXTENDED IA) $)^{9)}$, EVT can significantly reduce disability at 90 days compared to medical treatment (adjusted com-

- Received : December 5, 2017 •Revised : March 22, 2018 •Accepted : July 24, 2018

- Address for reprints : Jin Pyeong Jeon, M.D.

Department of Neurosurgery, Hallym University College of Medicine, 77 Sakju-ro, Chuncheon 24253, Korea

Tel : +82-33-240-5171, Fax : +82-33-240-9970, E-mail : jjs6553@daum.net

This is an Open Access article distributed under the terms of the Creative Commons Attribution Non-Commercial License (http://creativecommons.org/licenses/by-nc/4.0) which permits unrestricted non-commercial use, distribution, and reproduction in any medium, provided the original work is properly cited. 
mon odd ratio [cOR], 2.49; $p<0.001)$. Nevertheless, usefulness of EVT for acute M2 segment of middle cerebral artery (MCA) occlusion remains unclear because most results are obtained from patients with large artery occlusion in the anterior circulation ${ }^{3)}$. Goyal et al. ${ }^{9)}$ have reported that EVT has no favorable effect for M2 occlusion than medical treatment (cOR, 1.28; 95\% confidence interval [CI], 0.51-3.21). Compared to M1 segment of MCA, M2 shows smaller caliber size with thinner wall ${ }^{24)}$. Although vascular territories affected by acute ischemia of M2 occlusion are smaller than M1 occlusion, M2 occlusion can also lead to massive strokes that cause death or moderate to severe disability in approximately $50 \%$ of patients ${ }^{28)}$.

Due to advances in endovascular technologies, treatment outcomes of mechanical thrombectomy for acute M2 occlusion have been increasingly reported. Nevertheless, systematic review or meta-analysis of EVT outcomes, in particular technical aspects of successful recanalization and procedure-related complications, has not been well studied. Therefore, the aim of this study was to examine procedural outcomes of EVT for isolated M2 occlusion. In addition, procedural outcomes according to thrombus location were compared between M2 and M1 occlusion.

\section{MATERIALS AND METHODS}

\section{Literature search}

Literature searching through PubMed, Embase, and the Cochrane Central were searched using the following key words: "ischemic stroke", "endovascular therapy", "cerebral infarct", “intra-venous", "intra-arterial”, "fibrinolysis"6), "thrombolysis", "thrombectomy", "MCA", "M1", "M2", "hemorrhage", "embolus", “death", "peri-operative complications", and "mortality".

\section{Selection criteria and data abstraction}

Our inclusion criteria were : 1) studies that included patients presenting with acute M2 occlusion; 2) participants over 18 years; 3) endovascular treatments such as intra-arterial thrombolysis using tissue plasminogen activator (tPA) or urokinase and mechanical thrombectomy with stent retrieval, Merci retriever, or suction devices; 4) studies that included a minimum of 10 endovascular procedures through the common femoral $\operatorname{artery}^{15,16)}$; 5) clinical information on angiographic recanalization, clinical outcome, mortality, and complications can be extracted; and 6) randomized controlled studies, prospective or retrospective case-controlled studies with quality score over 5 on the Newcastle-Ottawa scale ${ }^{20)}$. Exclusion criteria were :

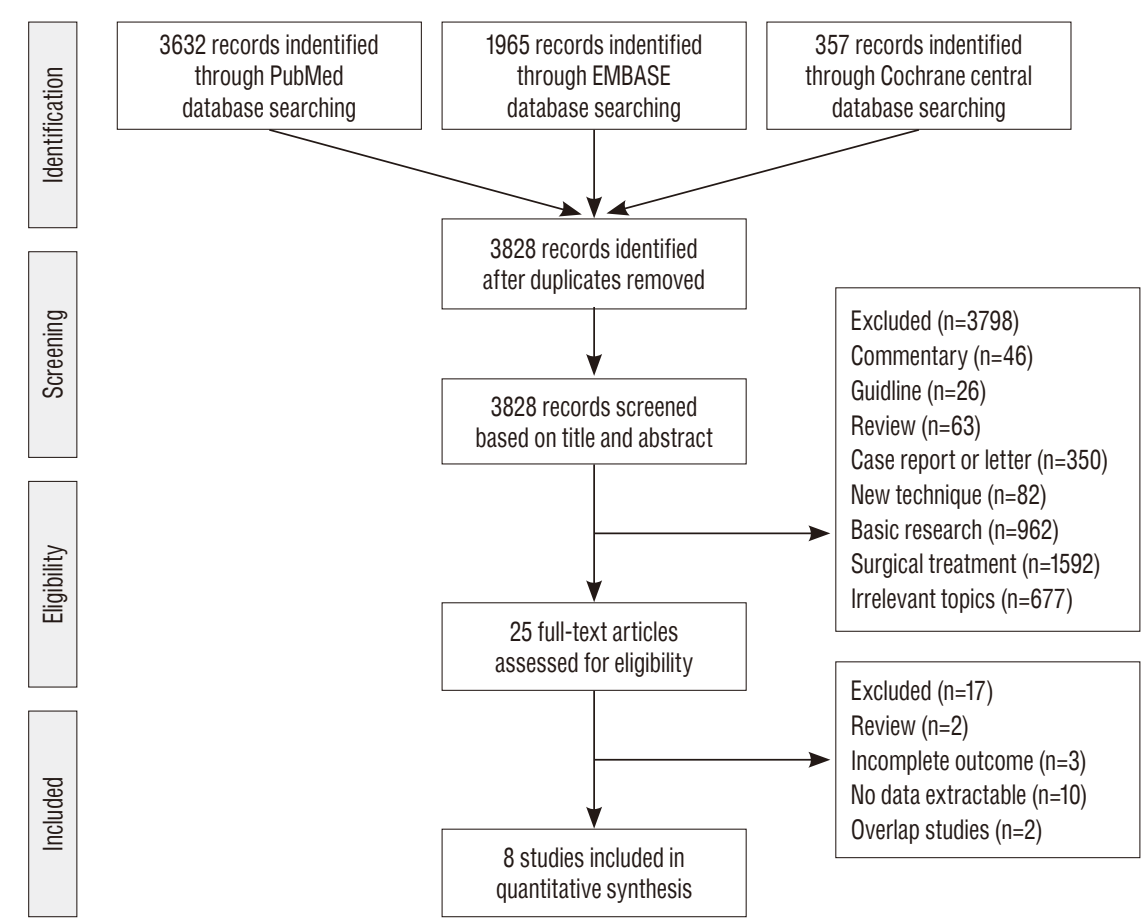

Fig. 1. Flow diagram showing the identification process of relevant studies. 


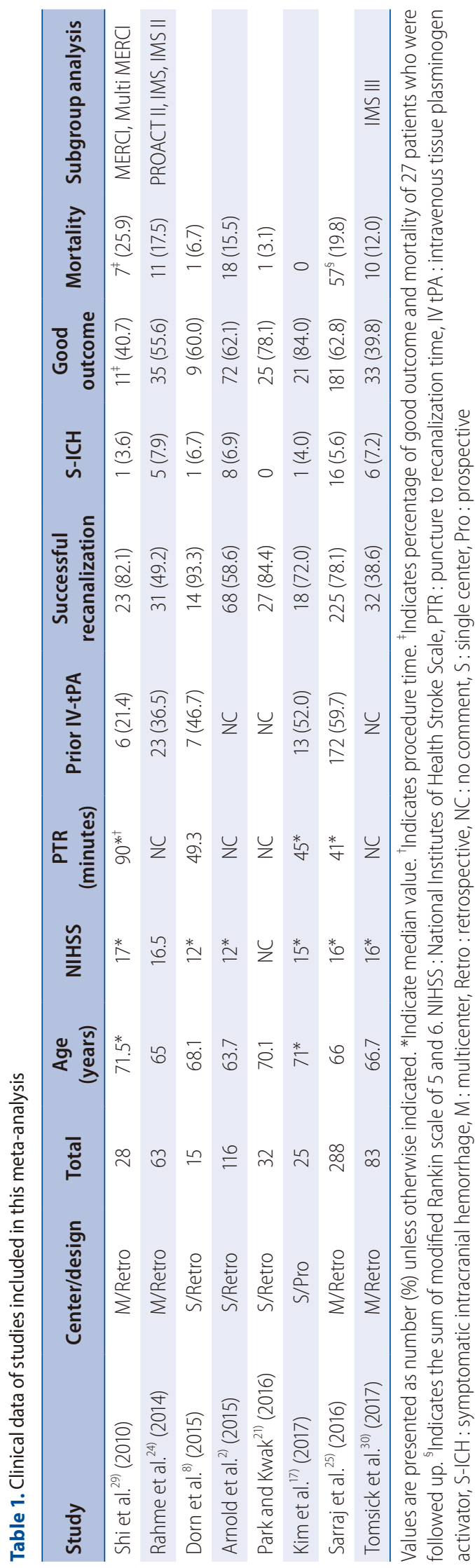

1) patients who did not show acute ischemic stroke; 2 ) incomplete data or unclear distinction between acute M1 and M2 occlusion; and 3) review articles or case reports ${ }^{10,13,14)}$.

The primary outcome was successful recanalization rate and symptomatic intracranial hemorrhage (S-ICH) after the procedure. Secondary outcomes were good clinical outcome after 3 months and mortality. Subgroup analysis compared procedural outcomes such successful recanalization and SICH according to thrombus location (M1 and M2). Successful recanalization was defined as thrombolysis in cerebral ischemia (TICI) or modified TICI $\geq 2 \mathrm{~b}$ or thrombolysis in Myocardial infarction grades 2 or $3^{1)}$. Good clinical outcome was defined when 3-month modified Rankin scale (mRS) score was $\leq 2$. S-ICH was defined as any cerebral hemorrhage concomitant with an increase of at least 4 National Institutes of Health Stroke Scale (NIHSS) score within 24 hours or resulting in death ${ }^{18)}$. An extensive electronic search was performed by an experienced researcher. Two authors (J.P.J. and C.H.K.) independently evaluated the eligibility of these studies and extracted data using a uniform and standardized form. Disagreements between the two authors were resolved by discussion and consultation with a third author. This meta-analysis was performed according to PRISMA guidelines ${ }^{19}$.

\section{Statistical analysis}

Cumulative incidence (event rate) and 95\% CI were estimated from each study. Dichotomous variables are presented as odds ratio (OR) with $95 \%$ CI. Heterogeneity was evaluated using $\mathrm{I}^{2}$ test. If $\mathrm{I}^{2}$ was less than $50 \%$, a fixed effect model was used $^{23)}$. Publication bias was determined using Egger's test of the intercept, and Begg and Mazumdar ${ }^{4)}$ rank correlation test. Comprehensive meta-analysis (CMA) software (CMA v2.2.064; Biostat, Englewood, NJ, USA) was used for all analysis. Statistical significance was accepted at $p<0.05$.

\section{RESULTS}

\section{Identification of relevant studies}

A flow diagram of the search process is detailed in Fig. 1. After screening records and deciding eligibility, eight articles were selected for analysis. Among them, three studies compared endovascular treatment outcomes between acute M1 and M2 occlusion. The mean age of patients used for each 


\begin{tabular}{|c|c|c|c|c|c|c|c|c|c|c|c|}
\hline \multirow[t]{2}{*}{ Study name } & \multicolumn{6}{|c|}{ Statistics for each study } & \multicolumn{5}{|c|}{ Event rate and $95 \% \mathrm{Cl}$} \\
\hline & Total & $\begin{array}{l}\text { Event } \\
\text { rate }\end{array}$ & $\begin{array}{l}\text { Lower } \\
\text { limit }\end{array}$ & $\begin{array}{l}\text { Upper } \\
\text { limit }\end{array}$ & Z-value & $p$-value & & & & & \\
\hline Shi et al. ${ }^{29)}(2010)$ & $23 / 28$ & 0.821 & 0.636 & 0.924 & 3.093 & 0.002 & & & & & \\
\hline Rahme et al. ${ }^{24)}$ (2014) & $31 / 63$ & 0.492 & 0.372 & 0.614 & -0.126 & 0.900 & & & & & \\
\hline Dorn et al..$^{8)}(2015)$ & $14 / 15$ & 0.933 & 0.648 & 0.991 & 2.550 & 0.011 & & & & & \\
\hline Arnold et al. ${ }^{2)}$ (2015) & $68 / 116$ & 0.586 & 0.495 & 0.672 & 1.848 & 0.065 & & & & & \\
\hline Park and Kwak ${ }^{211}$ (2016) & $27 / 32$ & 0.844 & 0.675 & 0.933 & 3.464 & 0.001 & & & & & \\
\hline Kim et al.." (2017) & $18 / 25$ & 0.720 & 0.518 & 0.860 & 2.120 & 0.034 & & & & & \\
\hline Sarraj et al. ${ }^{25)}(2016)$ & $225 / 288$ & 0.781 & 0.730 & 0.825 & 8.931 & 0.000 & & & & & \\
\hline \multirow[t]{2}{*}{ Tomsick et al. ${ }^{30)}(2017)$} & $32 / 83$ & 0.386 & 0.287 & 0.494 & -2.067 & 0.039 & & & & & \\
\hline & & 0.691 & 0.549 & 0.804 & 2.597 & 0.009 & & & & & \\
\hline \multicolumn{6}{|c|}{$\begin{array}{l}\text { Heterogeneity : } X^{2}=65.282, d f=7(p<0.001) ; I^{2}=89.277 \% \\
\text { Test for overall effect : } Z=2.597(p=0.009)\end{array}$} & & -1.00 & -0.50 & 0.00 & 0.50 & 1.00 \\
\hline
\end{tabular}

\begin{tabular}{|c|c|c|c|c|c|c|c|c|c|c|c|}
\hline \multirow[t]{2}{*}{ Study name } & \multicolumn{6}{|c|}{ Statistics for each study } & \multicolumn{5}{|c|}{ Event rate and $95 \% \mathrm{Cl}$} \\
\hline & Total & $\begin{array}{l}\text { Event } \\
\text { rate }\end{array}$ & $\begin{array}{l}\text { Lower } \\
\text { limit }\end{array}$ & $\begin{array}{l}\text { Upper } \\
\text { limit }\end{array}$ & Z-value & $p$-value & & & & & \\
\hline Shi et al. ${ }^{29)}(2010)$ & $1 / 28$ & 0.036 & 0.005 & 0.214 & -3.236 & 0.001 & & & 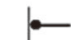 & & \\
\hline Rahme et al. ${ }^{24}(2014)$ & $5 / 63$ & 0.079 & 0.033 & 0.177 & -5.259 & 0.000 & & & - & & \\
\hline Dorn et al. ${ }^{8)}(2015)$ & $1 / 15$ & 0.067 & 0.009 & 0.352 & -2.550 & 0.011 & & & 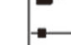 & & \\
\hline Arnold et al. ${ }^{2)}$ (2015) & $8 / 116$ & 0.069 & 0.035 & 0.132 & -7.103 & 0.000 & & & 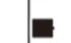 & & \\
\hline Park and Kwak ${ }^{21)}(2016)$ & $0 / 32$ & 0.015 & 0.001 & 0.201 & -2.929 & 0.003 & & & 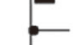 & & \\
\hline Kim et al. ${ }^{17)}(2017)$ & $1 / 25$ & 0.040 & 0.006 & 0.235 & -3.114 & 0.002 & & & 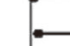 & & \\
\hline Sarraj et al. ${ }^{25)}(2016)$ & $16 / 288$ & 0.056 & 0.034 & 0.089 & -11.014 & 0.000 & & & 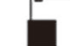 & & \\
\hline \multirow[t]{2}{*}{ Tomsick et al. ${ }^{30)}(2017)$} & $6 / 83$ & 0.072 & 0.033 & 0.152 & -6.021 & 0.000 & & & 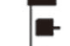 & & \\
\hline & & 0.061 & 0.045 & 0.083 & -16.388 & 0.000 & & & 1 & & \\
\hline $\begin{array}{l}\text { Heterogeneity : } X \\
\text { Test for overall e }\end{array}$ & $53, \mathrm{df}$ & $\begin{array}{l}=0.93 \\
(p<0.0\end{array}$ & $0.000 \%$ & & & & -1.00 & -0.50 & 0.00 & 0.50 & 1.00 \\
\hline
\end{tabular}

Fig. 2. Endovascular treatment outcomes of acute $M 2$ occlusion such as successful recanalization rate $(A)$ and symptomatic intracranial hemorrhage rate (B). $\mathrm{Cl}$ : confidence interval.

study ranged from 63.7 to 71 years. The median NIHSS score at admission ranged from 12 to 17 . Detailed baseline characteristics are summarized in Table 1.

\section{Procedural outcomes of acute $\mathrm{M} 2$ occlusion af- ter EVT}

A total of eight studies (650 patients) reported events of successful recanalization, S-ICH, good clinical outcome on 3-month follow-up and mortality. Of these, one article was excluded for mortality analysis because they did not provide such information. Successful recanalization rate at final angiogram was $69.1 \%$ (95\% CI, 54.9-80.4\%). The rate of S-ICH was 6.1\% (95\% CI, 4.5-8.3\%; Fig. 2). Good clinical outcome rate at 3-month follow-up after EVT was 59.4\% (95\% CI, 49.9-68.2\%). Mortality rate was $14.9 \%$ (95\% CI, 11.4-19.3\%).

\section{Comparisons of EVT outcomes according to thrombus location (M1 vs. M2)}

A total of 706 patients (M2 occlusion, $n=159$; M1 occlusion, $\mathrm{n}=547$ ) from the three studies ${ }^{2,8,29)}$ reported procedural outcomes according to thrombus location (Table 2). The number of successful recanalization was 105 (66.0\%) in M2 and 394 (72.0\%) in M1 occlusion. Successful recanalization (OR, 1.539; 95\% CI, 0.293-8.092; $p=0.610)$ and S-ICH (OR, 1.313; 95\% CI, $0.603-2.861 ; p=0.493)$ did not differ significantly between the two groups (Fig. 3). Good clinical outcome was more evident in M2 occlusion after EVT compared to that in M1 occlusion (OR, 1.639; 95\% CI, 1.135-2.368; $p=0.008$ ). Mortality did not differ significantly according to thrombus location (OR, 0.788; 95\% CI, 0.486-1.276; $p=0.332$ ). 
Table 2. Comparisons of endovascular treatment outcomes according to thrombus location (M1 vs. M2)

\begin{tabular}{lcccccccccc}
\hline Study & Location & Total & Age & NIHSS & $\begin{array}{c}\text { PTR } \\
\text { (minutes) }\end{array}$ & $\begin{array}{c}\text { Prior } \\
\text { IV-tPA }\end{array}$ & $\begin{array}{c}\text { Suceessful } \\
\text { recanalization }\end{array}$ & S-ICH & $\begin{array}{c}\text { Good } \\
\text { outcome }\end{array}$ & Mortality \\
\hline Shi et al..$^{29)}(2010)$ & M2 & 28 & $71.5^{*}$ & $17^{*}$ & $90^{* \dagger}$ & $6(21.4)$ & $23(82.1)$ & $1(3.6)$ & $11^{\ddagger}(40.7)$ & $7^{\ddagger}(25.9)$ \\
& M1 & 150 & $73.0^{*}$ & $18^{*}$ & $102^{* \dagger}$ & $21(14.0)$ & $90(60.0)$ & $10(6.7)$ & $46^{\S}(33.3)$ & $48^{\| 1}(32.9)$ \\
Dorn et al. ${ }^{8)}(2015)$ & M2 & 15 & 68.1 & $12^{*}$ & 49.3 & $7(46.7)$ & $14(93.3)$ & $1(6.7)$ & $9(60.0)$ & $1(6.7)$ \\
& M1 & 104 & 69.4 & $15^{*}$ & 55.6 & $53(51.0)$ & $79(76.0)$ & $6(5.8)$ & $45(43.3)$ & $22(21.2)$ \\
\hline Arnold et al..$^{2)}(2015)$ & M2 & 116 & 63.7 & $12^{*}$ & NC & NC & $68(58.6)$ & $8(6.9)$ & $72(62.1)$ & $18(15.5)$ \\
& M1 & 293 & 64.9 & $16^{*}$ & NC & NC & $225(76.8)$ & $13(4.4)$ & $145(49.5)$ & $50(17.1)$ \\
\hline
\end{tabular}

Values are presented as number (\%) unless otherwise indicated. ${ }^{*}$ Indicate median value. ${ }^{\dagger}$ Indicates procedure time. ${ }^{\ddagger}$ Indicates percentage of good outcome and mortality of 27 patients who were followed up. Indicates the percentage of good outcome at 3 months for 138 patients who were followed up. "Indicates the percentage of mortality of 146 patients who were followed up. NIHSS : National Institutes of Health Stroke Scale, PTR : puncture to recanalization time, IV tPA : intravenous tissue plasminogen activator, S-ICH : symptomatic intracranial hemorrhage, NC : no comment

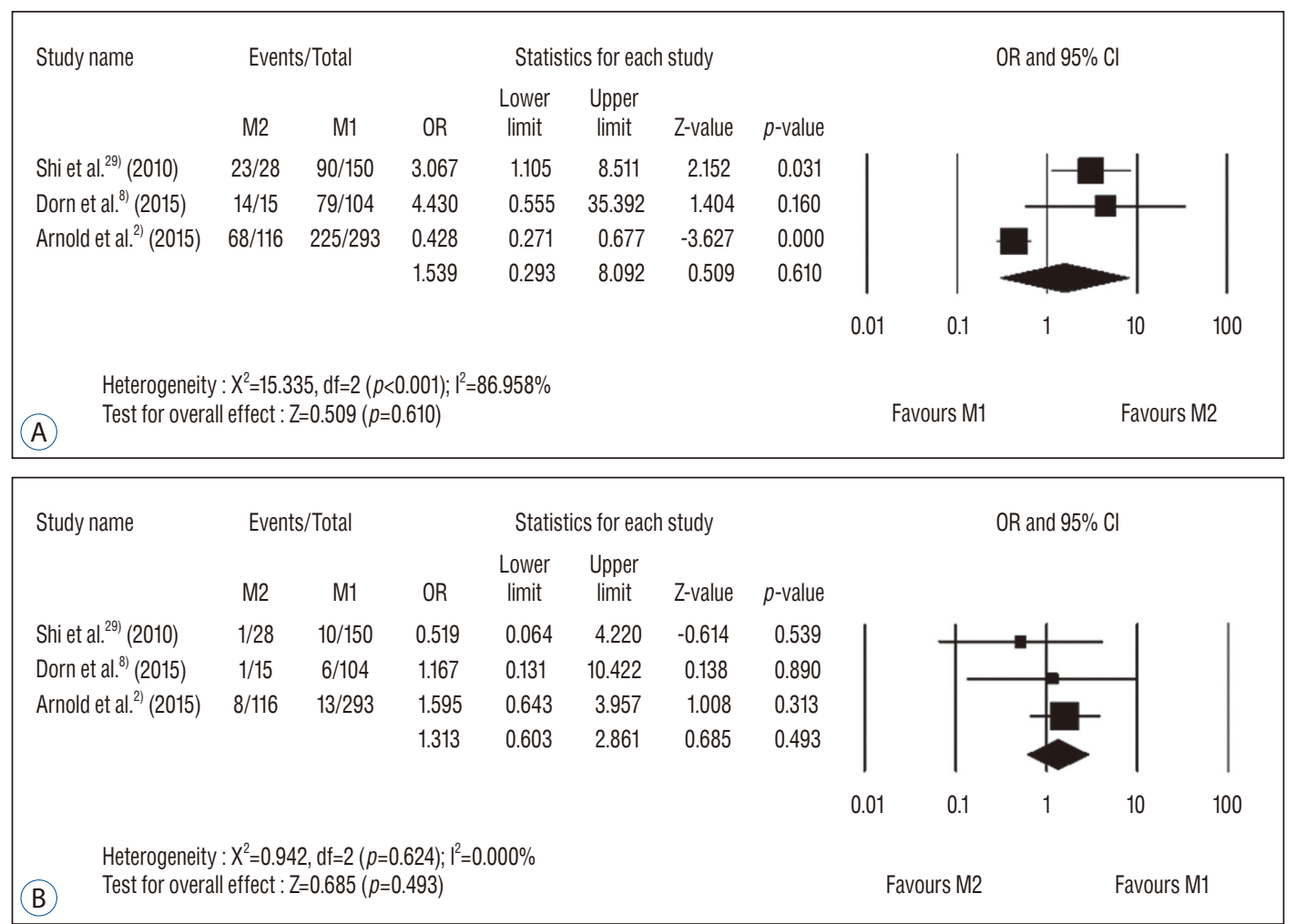

Fig. 3. Comparison of procedural outcomes according to thrombus location (M1 vs. M2) such as successful recanalization (A) and symptomatic intracranial hemorrhage (B). OR : odds ratio, $\mathrm{Cl}$ : confidence interval.

\section{Publication bias}

In the publication bias analysis for comparing successful recanalization according to thrombus location (M1 vs. M2), Egger's regression test revealed that the intercept was $3.98(95 \%$ $\mathrm{CI},-21.56$ to 29.53 ; $\mathrm{t}=1.98, \mathrm{df}=1$; two-tailed $p=0.30$ ). For rank correlation test, Kendall's tau was 0.33 with two-tailed $p$ value of 0.60. Regarding S-ICH according to thrombus location, Egger's regression test disclosed that the intercept was -1.13 (95\% CI, -11.31 to 9.04 ; $\mathrm{t}=1.42, \mathrm{df}=1$; two-tailed $p=0.40$ ). For rank correlation test, Kendall's tau was -0.33 with two-tailed $p$ value of 0.60 . Accordingly, there was no evidence of publication bias based on these comparisons. 


\section{DISCUSSION}

Due to advances in endovascular technologies, mechanical thrombectomy has been increasingly conducted for distal arterial occlusion ${ }^{12,31)}$. Kim et al. ${ }^{17)}$ have reported that direct aspiration has successful recanalization rate of $72.0 \%$ (vs. $87.5 \%$ in stent retriever group) and good functional outcome rate of $84.0 \%$ (75.0\% in stent retriever group) at 3-month follow up. Park and $\mathrm{Kwak}^{21)}$ have reported successful recanalization rate of 84\% (27 out of 32) and good functional outcome of 78\% (25 out of 32) at 3-month follow-up using Penumbra 4 MAX catheter (Penumbra, Alameda, CA, USA) without any occurrence of S-ICH. Nevertheless, beneficial effect of EVT for M2 occlusion compared to medical treatment remains questionable. Recently, a multicenter retrospective analysis ${ }^{25)}$ has compared treatment outcome between EVT and medical management for patients with acute M2 occlusion. Good outcomes at 3 months were more evident in the EVT group $(n=181,62.8 \%)$ than that in the medical treatment group $(n=83,35.4 \%)$ $(p=0.001)$. The rate of S-ICH did not differ significantly between the two groups (5.6\% in EVT vs. $2.1 \%$ in medical management; $p=0.10)$. Therefore, they suggested that EVT was more feasible for treating acute M2 occlusion than medical treatment.

Comparative studies of procedural outcomes according to thrombus location (M1 vs. M2) are important since it can provide indirect evidence of EVT for M2 occlusion. Sheth et al. ${ }^{28)}$ have found similar recanalization rate $(44 \%$ vs. $46 \%$ in $\mathrm{M} 1, p=0.31$ ) and discharge mRS $4-6$ rate ( $49 \%$ vs. $64 \%$ in M1; $p=0.13)$. The rate of S-ICH was significantly lower in M2 occlusion (21\%) than that in M1 occlusion (56\%) after EVT. Coutinho et al. ${ }^{7)}$ have performed a post hoc analysis to examine M2 occlusion outcomes after stent retriever thrombecto$m y$ in three multicenter prospective series ${ }^{22,26,27)}$. There was no significant differences in the rate of successful recanalization ( $85 \%$ vs. $82 \%$ in M1 occlusion; $p=0.82$ ), mortality ( $12 \%$ vs. $10 \%$ in M1 occlusion; $p=0.62)$ and S-ICH ( $2 \%$ vs. $2 \%$ in M1 occlusion; $p=1.00)$. M2 occlusion tended to be recanalized with lesser number of stent pass compared to M1 occlusion (mean, 1.4 vs. 1.7; $p=0.07$ ). On the contrary, Arnold et al. ${ }^{2}$ have reported better recanalization rate (76.8\%) in M1 occlusion than that $(68 \%)$ in M2 occlusion $(p<0.001)$. Such difference in the rate of mechanical thrombectomy ( $40.6 \%$ in M1 occlusion and 23.4\% in M2 occlusion) might be due to better recanalization in M1 occlusion. Our meta-analysis revealed no significant difference in procedural outcomes such as successful recanalization and S-ICH after EVT according to thrombus location. Accordingly, M2 occlusion can be given the same consideration as M1 occlusion if EVT is suitable ${ }^{28)}$.

Differences in endovascular devices and proportion of mechanical thrombectomy could affect treatment results for M2 occlusion. Stent retrieval thrombectomy provided better recanalization and clinical outcomes than Merci retrieval system. Broussalis et al. ${ }^{5}$ have reported that stent retrieval thrombectomy has successful recanalization rate of $82 \%$ and good outcome rate of $65 \%$ at 3 month follow up, which are higher than $62 \%$ and 35\%, respectively, in the Merci retrieval system. Hentschel et al. ${ }^{11}$, have also reported better recanalization rate of $97.01 \%$ and good clinical outcome rate of $61.67 \%$ at 3 months in patients treated with stent retriever thrombecvtomy (79.80\%) compared to those treated with non-stent retrieval thrombectomy (22.54\%). For M2 occlusion, solitaire stent yielded successful recanalization rate of $93.3 \%$, good outcome of $60.0 \%$, mortality of $6.7 \%$, and S-ICH of $6.7 \%{ }^{8}$. The Merci system has shown successful recanalization rate of $82.1 \%$, good outcome rate of $39.3 \%$, mortality of $25.0 \%$, and S-ICH rate of $3.6 \%{ }^{29)}$. Rahme et al. ${ }^{24)}$ have reported a pooled analysis of treatment outcome in $\mathrm{M} 2$ occlusion from PROACT II, IMS, and IMS II trials. Successful early reperfusion was noted in 31 patients (49.2\%). Good functional outcome rate was $58.1 \%$ in M2 occlusion with successful recanlaization. They found that patients with acute M2 occlusion did not show positive correlation between reperfusion status and clinical outcome at 3 months $(p=0.80)$. However, the PROACT II study compared treatment outcomes between IA recombinant prourokinase with low-dose intravenous (IV) heparin and low-dose heparin excluding mechanical clot disruption. The IMS trial also determined the efficacy of combined IV and IA tPA for acute ischemic stroke. Sheth et al. $^{28)}$ have reported a successful recanalization rate of $44.2 \%$ after EVT. In their study, IA tPA ( $\mathrm{n}=33,63.5 \%)$ was used the most frequently, followed by the Merci system ( $n=10,19.2 \%)$. Accordingly, larger studies are needed in consideration of treatment strategies (thrombolysis using drug or devices; or stent retriever or direct aspiration) to determine the beneficial effect of EVT in acute M2 occlusion on clinical outcome.

This study has some limitations. First, most studies of this investigation were retrospective in nature. Second, several fac- 
tors such as endovascular devices and prior use of IV tPA might have affected clinical outcomes. Third, definition of M2 occlusion can be different according to investigators. Accordingly, consensus about anatomical M2 definition is needed to analyze treatment outcome ${ }^{30)}$. Fourths, difference in stroke severity at admission could be a confounding factor in interpreting these results, especially analyzing clinical outcome. This was because patients with M2 occlusions often present with few to moderate symptoms and may be therefore not considered for EVT. In this study, we aimed to assess technical aspects such as successful recanalization and S-ICH after the procedure. Until now, a direct comparative analysis of clinical outcomes between EVT and medical treatment for M2 occlusion has not been widely performed due to high probability of procedural risk. Our results demonstrated that procedural outcomes were not significantly different between M1 and M2 occlusion after EVT, although M2 branches were small-caliber arteries. Accordingly, further studies delineating specific subgroups of M2 occlusion who can benefit from EVT compared to medical treatment can be justified.

\section{CONCLUSION}

Our meta-analysis showed that EVT for M2 occlusion provided an overall successful recanalization rate of $69.1 \%$ and SICH rate of $6.1 \%$. No significant difference in successful recanalization and S-ICH was noted according to thrombus location. EVT seems to be technically feasible for acute M2 occlusion. Direct comparative studies between EVT and medical treatment for M2 occlusion are needed further to find specific beneficiary group in patient with M2 occlusion.

\section{CONFLICTS OF INTEREST}

No potential conflict of interest relevant to this article was reported.

\section{INFORMED CONSENT}

This type of study does not require informed consent.

\section{- Acknowledgements}

This study was supported by Hallym University Research Fund (HURF-2017-54) and National Research Foundation of Korea grant funded by the Ministry of Science, Information and Communication Technologies and Future Planning of the Korea Government (No. 2017M3A9E8033223).

\section{References}

1. Almekhlafi MA, Menon BK, Freiheit EA, Demchuk AM, Goyal M : A meta-analysis of observational intra-arterial stroke therapy studies using the Merci device, Penumbra system, and retrievable stents. AJNR Am J Neuroradiol 34 : 140-145, 2013

2. Arnold M, Slezak A, El-Koussy M, Lüdi R, Findling O, Mono ML, et al. : Occlusion location of middle cerebral artery stroke and outcome after endovascular treatment. Eur Neurol 74 : 315-321, 2015

3. Badhiwala JH, Nassiri F, Alhazzani W, Selim MH, Farrokhyar F, Spears J, et al. : Endovascular thrombectomy for acute ischemic stroke: a metaanalysis. JAMA 314 : 1832-1843, 2015

4. Begg CB, Mazumdar $\mathrm{M}$ : Operating characteristics of a rank correlation test for publication bias. Biometrics 50 : 1088-1101, 1994

5. Broussalis E, Trinka E, Hitzl W, Wallner A, Chroust V, Killer-Oberpfalzer $M$ : Comparison of stent-retriever devices versus the Merci retriever for endovascular treatment of acute stroke. AJNR Am J Neuroradiol 34 : 366-372, 2013

6. Bush CK, Kurimella D, Cross LJ, Conner KR, Martin-Schild S, He J, et al. : Endovascular treatment with stent-retriever devices for acute ischemic stroke: a meta-analysis of randomized controlled trials. PLoS One 11 : e0147287, 2016

7. Coutinho JM, Liebeskind DS, Slater LA, Nogueira RG, Baxter BW, Levy $\mathrm{El}$, et al. : Mechanical thrombectomy for isolated M2 occlusions: a post hoc analysis of the STAR, SWIFT, and SWIFT PRIME studies. AJNR Am J Neuroradiol 37 : 667-672, 2016

8. Dorn F, Lockau H, Stetefeld H, Kabbasch C, Kraus B, Dohmen C, et al. : Mechanical thrombectomy of M2-occlusion. J Stroke Cerebrovasc Dis 24 : 1465-1470, 2015

9. Goyal M, Menon BK, van Zwam WH, Dippel DW, Mitchell PJ, Demchuk AM, et al. : Endovascular thrombectomy after large-vessel ischaemic stroke: a meta-analysis of individual patient data from five randomised trials. Lancet $387:$ 1723-1731, 2016

10. Grech R, Pullicino R, Thornton J, Downer J : An efficacy and safety comparison between different stentriever designs in acute ischaemic stroke: a systematic review and meta-analysis. Clin Radiol 71 : 48-57, 2016

11. Hentschel KA, Daou B, Chalouhi N, Starke RM, Clark S, Gandhe A, et al. : Comparison of non-stent retriever and stent retriever mechanical thrombectomy devices for the endovascular treatment of acute ischemic stroke. J Neurosurg 126 : 1123-1130, 2017 
12. Jankowitz B, Grandhi R, Horev A, Aghaebrahim A, Jadhav A, Linares G, et al. : Primary manual aspiration thrombectomy (MAT) for acute ischemic stroke: safety, feasibility and outcomes in 112 consecutive patients. J Neurointerv Surg 7 : 27-31, 2015

13. Jeon JP, Kim JE : A recent update of clinical and research topics concerning adult moyamoya disease. J Korean Neurosurg Soc 59 : 537-543, 2016

14. Jeon JP, Kim JE, Cho WS, Bang JS, Son YJ, Oh CW : Meta-analysis of the surgical outcomes of symptomatic moyamoya disease in adults. J Neurosurg $128:$ 793-799, 2018

15. Jeon JP, Kim SE, Kim CH : Endovascular treatment of acute ischemic stroke in octogenarians: a meta-analysis of observational studies. Clin Neurol Neurosurg $161:$ 70-77, 2017

16. Jeon JP, Kim SE, Kim CH: Primary suction thrombectomy for acute ischemic stroke: a meta-analysis of the current literature. Clin Neurol Neurosurg $163:$ 46-52, 2017

17. Kim YW, Son S, Kang DH, Hwang YH, Kim YS : Endovascular thrombectomy for M2 occlusions: comparison between forced arterial suction thrombectomy and stent retriever thrombectomy. J Neurointerv Surg 9 : 626-630, 2017

18. Lapergue B, Blanc R, Guedin P, Decroix JP, Labreuche J, Preda C, et al. : $A$ direct aspiration, first pass technique (ADAPT) versus stent retrievers for acute stroke therapy: an observational comparative study. AJNR Am J Neuroradiol 37 : 1860-1865, 2016

19. Liberati A, Altman DG, Tetzlaff J, Mulrow C, Gøtzsche PC, loannidis JP, et al. : The PRISMA statement for reporting systematic reviews and meta-analyses of studies that evaluate healthcare interventions: explanation and elaboration. BMJ 339 : b2700, 2009

20. Lo CK, Mertz D, Loeb M : Newcastle-Ottawa Scale: comparing reviewers' to authors' assessments. BMC Med Res Methodol $14:$ 45, 2014

21. Park JS, Kwak HS : Manual aspiration thrombectomy using penumbra catheter in patients with acute M2 occlusion : a single-center analysis. J Korean Neurosurg Soc 59 : 352-356, 2016

22. Pereira VM, Gralla J, Davalos A, Bonafé A, Castaño C, Chapot R, et al. : Prospective, multicenter, single-arm study of mechanical thrombectomy using Solitaire Flow Restoration in acute ischemic stroke. Stroke 44 : 2802-2807, 2013

23. Qian C, Yu X, Li J, Chen J, Wang L, Chen G : The efficacy of surgical treatment for the secondary prevention of stroke in symptomatic moyamoya disease: a meta-analysis. Medicine (Baltimore) 94 : e2218, 2015

24. Rahme R, Yeatts SD, Abruzzo TA, Jimenez $L$, Fan $L$, Tomsick TA, et al. : Early reperfusion and clinical outcomes in patients with $\mathrm{M} 2$ occlusion: pooled analysis of the PROACT II, IMS, and IMS II studies. J Neurosurg $121: 1354-1358,2014$

25. Sarraj A, Sangha N, Hussain MS, Wisco D, Vora N, Elijovich L, et al. : Endovascular therapy for acute ischemic stroke with occlusion of the middle cerebral artery M2 segment. JAMA Neurol 73 : 1291-1296, 2016

26. Saver JL, Goyal M, Bonafe A, Diener HC, Levy El, Pereira VM, et al. : Solitaire ${ }^{\mathrm{TM}}$ with the Intention for Thrombectomy as Primary Endovascular Treatment for Acute Ischemic Stroke (SWIFT PRIME) trial: protocol for a randomized, controlled, multicenter study comparing the Solitaire revascularization device with IV tPA with IV IPA alone in acute ischemic stroke. Int J Stroke $10:$ 439-448, 2015

27. Saver JL, Jahan R, Levy El, Jovin TG, Baxter B, Nogueira RG, et al. : Solitaire flow restoration device versus the Merci Retriever in patients with acute ischaemic stroke (SWIFT): a randomised, parallel-group, noninferiority trial. Lancet 380 : 1241-1249, 2012

28. Sheth SA, Yoo B, Saver JL, Starkman S, Ali LK, Kim D, et al. : M2 occlusions as targets for endovascular therapy: comprehensive analysis of diffusion/perfusion MRI, angiography, and clinical outcomes. J Neurointerv Surg $7:$ 478-483, 2015

29. Shi ZS, Loh Y, Walker G, Duckwiler GR; MERCI and Multi-MERCI Investigators : Clinical outcomes in middle cerebral artery trunk occlusions versus secondary division occlusions after mechanical thrombectomy: pooled analysis of the mechanical embolus removal in cerebral ischemia (MERCI) and multi MERCI trials. Stroke 41 : 953-960, 2010

30. Tomsick TA, Carrozzella J, Foster $L$, Hill MD, von Kummer R, Goyal M, et al. : Endovascular therapy of M2 occlusion in IMS III: role of M2 segment definition and location on clinical and revascularization outcomes. AJNR Am J Neuroradiol 38 : 84-89, 2017

31. Turk AS, Spiotta A, Frei D, Mocco J, Baxter B, Fiorella D, et al. : Initial clinical experience with the ADAPT technique: a direct aspiration first pass technique for stroke thrombectomy. J Neurointerv Surg 6 : 231237, 2014 